\title{
WHO EXPERT COMMITTEE ON DRUG DEPENDENCE
}

Thirty-fourth Report

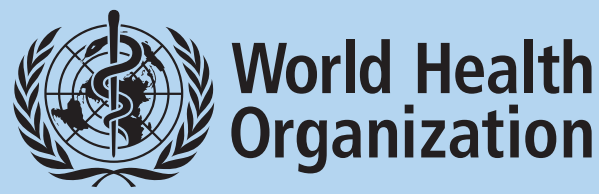


The World Health Organization was established in 1948 as a specialized agency of the United Nations serving as the directing and coordinating authority for international health matters and public health. One of WHO's constitutional functions is to provide objective and reliable information and advice in the field of human health, a responsibility that it fulfils in part through its extensive programme of publications.

The Organization seeks through its publications to support national health strategies and address the most pressing public health concerns of populations around the world. To respond to the needs of Member States at all levels of development, WHO publishes practical manuals, handbooks and training material for specific categories of health workers; internationally applicable guidelines and standards; reviews and analyses of health policies, programmes and research; and state-of-the-art consensus reports that offer technical advice and recommendations for decision-makers. These books are closely tied to the Organization's priority activities, encompassing disease prevention and control, the development of equitable health systems based on primary health care, and health promotion for individuals and communities. Progress towards better health for all also demands the global dissemination and exchange of information that draws on the knowledge and experience of all WHO's Member countries and the collaboration of world leaders in public health and the biomedical sciences.

To ensure the widest possible availability of authoritative information and guidance on health matters, WHO secures the broad international distribution of its publications and encourages their translation and adaptation. By helping to promote and protect health and prevent and control disease throughout the world, WHO's books contribute to achieving the Organization's principal objective - the attainment by all people of the highest possible level of health.

The WHO Technical Report Series makes available the findings of various international groups of experts that provide $\mathrm{WHO}$ with the latest scientific and technical advice on a broad range of medical and public health subjects. Members of such expert groups serve without remuneration in their personal capacities rather than as representatives of governments or other bodies; their views do not necessarily reflect the decisions or the stated policy of WHO. An annual subscription to this series, comprising about six such reports, costs CHF 168.00/US\$ 151.00 (CHF 128.40/US\$ 115.00 in developing countries). For further information, please contact: WHO Press, World Health Organization, 20 avenue Appia, 1211 Geneva 27, Switzerland (tel. +41 22791 3264; fax: +41 22791 4857; e-mail: bookorders@who.int; order on line: http://www. who.int/bookorders). 


\section{WHO EXPERT COMMITTEE ON DRUG DEPENDENCE}

Thirty-fourth Report

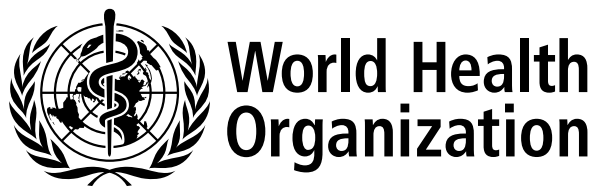


WHO Library Cataloguing-in-Publication Data

WHO Expert Committee on Drug Dependence. Meeting (34th: 2006: Geneva, Switzerland) WHO Expert Committee on Drug Dependence: thirty-fourth report.

(WHO technical report series; no. 942)

1. Psychotropic drugs - classification. 2. Psychotropic drugs - pharmacology. 3. Drug and narcotic control. 4. Treaties. 5. Guidelines. I. World Health Organization. II. Title. III. Series.

ISBN 9241209429

(NLM classification: WM 270)

ISBN 9789241209427

ISSN 0512-3054

\section{(c) World Health Organization 2006}

All rights reserved. Publications of the World Health Organization can be obtained from WHO Press, World Health Organization, 20 Avenue Appia, 1211 Geneva 27, Switzerland (tel.: +41 22791 3264; fax: +4122 7914857; e-mail: bookorders@who.int). Requests for permission to reproduce or translate WHO publications - whether for sale or for noncommercial distribution - should be addressed to WHO Press, at the above address (fax: +41 22791 4806; e-mail: permissions@who.int).

The designations employed and the presentation of the material in this publication do not imply the expression of any opinion whatsoever on the part of the World Health Organization concerning the legal status of any country, territory, city or area or of its authorities, or concerning the delimitation of its frontiers or boundaries. Dotted lines on maps represent approximate border lines for which there may not yet be full agreement.

The mention of specific companies or of certain manufacturers' products does not imply that they are endorsed or recommended by the World Health Organization in preference to others of a similar nature that are not mentioned. Errors and omissions excepted, the names of proprietary products are distinguished by initial capital letters.

All reasonable precautions have been taken by the World Health Organization to verify the information contained in this publication. However, the published material is being distributed without warranty of any kind, either expressed or implied. The responsibility for the interpretation and use of the material lies with the reader. In no event shall the World Health Organization be liable for damages arising from its use.

This publication contains the collective views of an international group of experts and does not necessarily represent the decisions or the stated policy of the World Health Organization. 


\section{Contents}

1. Introduction 1

2. Critical review of psychoactive substances 1

2.1 Substances recommended for changes in scheduling 2

2.1.1 Dronabinol (INN) 2

2.1.2 Oripavine 4

2.2 Other substances critically reviewed 5

2.2.1 Buprenorphine (INN) 5

2.2.2 Butorphanol (INN) 8

2.2.3 Ketamine (INN) 9

2.2.4 Khat (Catha edulis Forsk.) 10

2.2.5 Zopiclone (INN) 12

3. Pre-review of psychoactive substances 13

$\begin{array}{ll}3.1 \text { Gamma-hydroxybutyric acid } & 13\end{array}$

$\begin{array}{ll}3.2 \text { Tramadol (INN) } & 14\end{array}$

4. Substances identified for future pre-review 15

4.1 Gamma-butyrolactone (GBL) 15

4.2 1,4-Butanediol 16

5. Guidelines for the WHO review of dependence-producing $\begin{array}{ll}\text { psychoactive substances for international control } & 16\end{array}$

5.1 Amending the current version of the guidelines 16

5.2 Interpretation of specific aspects of the guidelines 17

5.3 Access to information necessary for the evaluation of substances 18

6. Other matters 18

6.1 Activities of the European Monitoring Centre
for Drugs and Drug Addiction (EMCDDA)

6.2 Use of pharmacovigilance data for the assessment of dependence and abuse potential (procedures and methodology) 19

6.3 Promotion of education and information on the appropriate $\begin{array}{ll}\text { use of psychoactive drugs } & 19\end{array}$

6.4 Impact of international control on medical availability
of substances

$\begin{array}{ll}\text { Acknowledgements } & 23\end{array}$

$\begin{array}{ll}\text { References } & 23\end{array}$ 



\section{WHO Expert Committee on Drug Dependence}

Geneva, 28-31 March 2006

\section{Members*}

Dr L. De Lima, IAHPC Executive Director, International Association for Hospice and Palliative Care, Houston, TX, USA (Rapporteur)

Professor R. Fernandopulle, Senior Lecturer, Department of Pharmacology, Faculty of Medicine, University of Colombo, Colombo, Sri Lanka

Professor C.R. Schuster, Director, Substance Abuse Research Division \& Addiction Research Institute, Wayne State University, Department of Psychiatry and Behavioral Neurosciences, Detroit, MI, USA

Professor S. Suryawati, Director, Centre for Clinical Pharmacology and Medicine Policy Studies, Gadjah Mada University, Yogyakarta, Indonesia (Vice-chairperson)

Professor T. Suzuki, Department of Toxicology, School of Pharmacy, Hoshi University, Tokyo, Japan

Dr V. Verachai, Deputy Director, Thanyarak Institute on Drug Abuse, Department of Medical Services, Pathumtani, Thailand

Professor W. Wieniawski, Polish Pharmaceutical Society, Warsaw, Poland (Chairperson)

\section{Representatives of other organizations}

College on Problems on Drug Dependence (WHO Collaborating Centre for Research and Training in Drug Dependence)

Dr L.S. Harris, Harvey Haag, Professor, Medical College of Virginia, Pharmacology and Toxicology, Virginia Commonwealth University, Richmond, VA, USA

European Monitoring Centre for Drugs and Drug Addiction (EMCDDA)

Dr R. Sedefov, Project Manager New Drugs and Scientific Committee, European Monitoring Centre for Drugs and Drug Addiction, Lisbon, Portugal (Special guest at first part of meeting)

International Narcotics Control Board (INCB)

Dr P.O. Emafo, First Vice-President of the Board, INCB, Vienna, Austria

P. Pachta, Deputy Secretary of the Board and Chief, Narcotics Control and Estimates Section, INCB Secretariat, United Nations Office on Drugs and Crime, Vienna, Austria

Joint United Nations Programme on HIVIAIDS (UNAIDS)

Dr A. Chatterjee, Senior Adviser, Prevention, Policy Evidence and Partnerships Department, Joint United Nations Programme on HIV/AIDS (UNAIDS), Geneva, Switzerland

\footnotetext{
* Unable to attend: Professor M.S. Bourin, Department of Pharmacology, Faculty of Medicine, University of Nantes, Nantes, France; Dr E.M.A. Ombaka, Director, Ecumenical Pharmaceutical Network, Westlands, Nairobi, Kenya.
} 
United Nations Office on Drugs and Crime (UNODC)

Dr B. Remberg, Scientific Affairs Officer, Laboratory and Scientific Section, UNODC, Vienna, Austria

C. Volz, Chief, Treaty and Legal Affairs Branch, UNODC, Vienna, Austria

International Federation of Pharmaceutical Manufacturers and Associations (IFPMA)

Dr Y. Juillet, Chairperson of the Regulatory Policy and Technical Standards Committee, IFPMA, Geneva, Switzerland

\section{Secretariat}

Dr B. Brands, Acting Head, Addiction Medicine Clinic, Assistant Professor, Centre for Addiction and Mental Health, Assistant Professor, Department of Pharmacology, University of Toronto, Toronto, Ontario, Canada (Temporary adviser)

Dr S. Elliott, Senior Clinical Scientist, Head of Forensic Toxicology Section, Regional Laboratory for Toxicology, City Hospital, Birmingham, England (Temporary adviser)

Dr E.J.M. Pennings, Biochemist-Toxicologist, Oegstgeest, The Netherlands (Temporary adviser)

Dr V. Poznyak, Coordinator, Management of Substance Abuse, WHO, Geneva, Switzerland

Dr L. Rägo, Coordinator, Quality Assurance and Safety: Medicines, WHO, Geneva, Switzerland

Dr W.K. Scholten, Technical Officer, Quality Assurance and Safety: Medicines, WHO, Geneva, Switzerland (Secretary)

Dr T. Schwalbach, Head Anaesthesiologist, Anaesthetic Department, Maputo Central Hospital, Maputo, Mozambique (Temporary adviser) 


\section{Introduction}

The WHO Expert Committee on Drug Dependence met in Geneva from 28 to 31 March 2006. Dr Howard Zucker, Assistant Director-General, Health Technology and Pharmaceuticals, and Dr Hans Hogerzeil, Director of Medicines Policy and Standards, welcomed the participants. Dr Zucker stressed the importance of balancing the need for preventing diversion of therapeutic substances with abuse potential by means of appropriate controls against the need for ensuring access to these substances for therapeutic use. The data from the International Narcotics Control Board (INCB) show that in many countries there is underuse of the narcotic analgesics needed for patients.

Dr Hogerzeil emphasized that the evaluation of substances by this Committee is one of the few tasks of WHO, if not the only one, based on international treaties. It is a mandatory task.

The meeting was opened by Dr L. Rägo, Coordinator, Quality Assurance and Safety: Medicines, who emphasized the significant role this Committee has played in the implementation of the international drug control system based on the existing drug control Conventions. As a specialized agency of the United Nations, WHO is responsible for conducting the medical and scientific evaluation of dependence-producing substances and makes recommendations to the Commission on Narcotic Drugs of the United Nations concerning the level of international control to be applied to them. As WHO has the sole responsibility for this function, no psychoactive substance can be controlled internationally without first being evaluated by WHO.

\section{Critical review of psychoactive substances}

A critical review is conducted by the Expert Committee in any of the following cases:

(1) There has been notification from a Party to the 1961 (1) or the 1971 Convention (2) concerning the scheduling of a substance.

(2) There has been an explicit request from the United Nations Commission on Narcotic Drugs to review a substance.

(3) Pre-review of a substance has resulted in a recommendation for critical review.

(4) Information is brought to the attention of WHO that a substance presenting an especially serious risk to public health and society, and of no recognized therapeutic use by any Member State is clandestinely manufactured. 
If therapeutic use of the substance is confirmed subsequently by any Member State in respect of case (4), the substance shall be subject to a pre-review.

Three of the substances under critical review at the present meeting had been pre-reviewed at the thirty-third meeting of the Committee (3) and recommended for critical review. Two of the substances (buprenorphine and dronabinol) had undergone critical review at the previous meeting.

\subsection{Substances recommended for changes in scheduling}

\subsubsection{Dronabinol (INN)}

\section{Substance identification}

Dronabinol (INN) is $(6 \mathrm{a} R, 10 \mathrm{a} R)-6 \mathrm{a}, 7,8,10 \mathrm{a}$-tetrahydro-6,6,9-trimethyl-3pentyl-6- $H$-dibenzo[ $b, d]$ pyran-1-ol. It is the $(6 \mathrm{a} R, 10 \mathrm{a} R)$-stereoisomer of delta-9-tetrahydrocannabinol and is also designated (-)-trans-delta-9-tetrahydrocannabinol.

Other stereoisomers of delta-9-tetrohydrocannabinol are: $(6 \mathrm{a} R, 10 \mathrm{a} S)$-, $(6 \mathrm{a} S, 10 \mathrm{a} R)-$ and $(6 \mathrm{a} S, 10 \mathrm{a} S)-$, also known as $(-)$-cis-, $(+)-c i s-$ and $(+)-$ trans-, respectively. Delta-9-tetrohydrocannabinol has two racemates, $(6 \mathrm{a} R S, 10 \mathrm{a} R S)$ - and $(6 \mathrm{a} R S, 10 \mathrm{a} S R)-$, also known as $( \pm)$-trans- and $( \pm)$-cis-, respectively.

Originally, all isomers of tetrahydrocannabinol were included in Schedule I of the 1971 Convention. This was later amended to include seven named constitutional isomers and their respective stereochemical variants. The term "constitutional isomers" used above has recently been introduced by the International Union of Pure and Applied Chemistry (IUPAC) to replace the traditionally used term "positional isomers".

The term "stereochemical variants" used in the 1971 Convention and mentioned above is equivalent to the term "stereoisomers", which is at present much more widely used in the chemical and related literature. Both terms cover geometric isomers and optical isomers.

\section{Previous review}

Delta-9-tetrahydrocannabinol was included in Schedule I of the 1971 Convention at the time of its adoption. At its twenty-sixth meeting, the Committee recommended that dronabinol be moved to Schedule II, while keeping the other isomers and their stereochemical variants in Schedule I (4). This proposal was rejected at the 11th Special Session of the Commission on Narcotic Drugs, and the Committee reviewed the question again at its 
twenty-seventh meeting when it recommended that all the stereochemical variants of delta-9-tetrahydrocannabinol be rescheduled to Schedule II (5). This recommendation was adopted by the United Nations Commission on Narcotic Drugs at its 34th session (6). At its thirty-second meeting, the Committee pre-reviewed dronabinol and recommended its critical review for consideration of the rescheduling on the grounds that the rate of abuse of dronabinol was extremely low (7).

Delta-9-tetrahydrocannabinol was critically reviewed by the Expert Committee on Drug Dependence at its thirty-third meeting in September 2002 (3). On the basis of the available data the Committee considered that dronabinol should be rescheduled to Schedule IV of the 1971 Convention. However, no further procedural steps were taken. Therefore, the existing critical review report was updated, including information from recent scientific publications, to enable the Committee to finalize the process of critical review.

\section{Similarity to known substances and effects on the central nervous system}

Dronabinol is the main active principle of cannabis and has similar effects on mood, perception and the cardiovascular system. The cannabis plant contains a "natural mixture" of around 70 different cannabinoids, and also contains flavonoids and terpenes, as well as many other substances. Therefore the pharmacological properties of natural cannabis and dronabinol are not identical.

\section{Dependence potential}

Animal studies have demonstrated that, like other drugs of abuse, dronabinol acts as a drug reinforcer. Physical dependence, as shown by withdrawal syndrome following chronic administration, has also been demonstrated. Reinforcing effects and physical dependence have also been described in human studies.

\section{Actual abuse and/or evidence of likelihood of abuse}

The abuse of dronabinol is currently rare and there have been very few specific reports of its occurrence. In response to the WHO questionnaires only the United States mentioned instances of abuse of delta-9-tetrahydrocannabinol. At present, the quantity produced by licit manufacture is limited. In the United States, which is the major manufacturing country, the abuse of dronabinol medicinal preparations is reported to be very low and there are no reports of diversion of the pharmaceutical product. 


\section{Therapeutic usefulness}

Dronabinol preparations have been used in a limited number of countries in the treatment of nausea and vomiting associated with cancer chemotherapy in patients who have failed to respond adequately to conventional antiemetic treatments and in the treatment of anorexia associated with weight loss in patients with acquired immunodeficiency syndrome (AIDS). It has also been indicated in the treatment of chronic pain (e.g. in multiple sclerosis, neuropathic disorders and arthritis), neurological disorders and appetite loss in cachexia, and is being evaluated for use in various other clinical situations.

\section{Recommendation}

The Committee reconsidered the recommendation of the thirty-third Expert Committee after considering the updated critical review report. The Committee concluded that dronabinol constitutes a substantial risk to public health. However this risk is different from those related to cannabis - controlled under the 1961 Convention. The substance has a moderate therapeutic usefulness and as a result of continuing clinical research its medical use is likely to increase. Therefore, the Committee recommended that dronabinol (INN) and its stereoisomers should be rescheduled from Schedule II to Schedule III of the 1971 Convention.

To avoid legal and forensic chemical problems that may arise in some countries when placing stereoisomers of the same substance under different control systems, the Committee indicated that the recommendation pertains to all stereoisomeric forms of delta-9-tetrahydrocannabinol as specified above.

\subsubsection{Oripavine}

\section{Substance identification}

Oripavine, 3-O-demethylthebaine, or 6,7,8,14-tetradehydro-4,5-alpha-epoxy6-methoxy-17-methylmorphinan-3-ol is a phenanthrene alkaloid contained in species of the Papaver plant. It is a major metabolite of thebaine.

\section{Previous review}

Oripavine was pre-reviewed at the thirty-third meeting of the Expert Committee in 2002 (3). The reason for pre-review in 2002 was that oripavine is a substance that is convertible into thebaine, and because thebaine is in turn convertible into morphine. Thebaine and morphine are both in Schedule I of the 1961 Convention. Owing to uncertainties regarding the scheduling of oripavine based on the additional possibility of applying the 1988 
Convention (8), the Committee did not finalize this review at its thirtythird meeting, but asked WHO for clarification of issues related to the conversion of precursors into scheduled substances. Subsequent clarification of these issues allowed the Committee to come to a conclusion at its thirty-fourth meeting.

\section{Recommendation}

The Committee decided that oripavine is a substance that is easily convertible into thebaine and other substances controlled in Schedule I of the 1961 Convention. Hence, the Committee recommended that oripavine be scheduled, like the substances mentioned, in Schedule I of the 1961 Convention.

\subsection{Other substances critically reviewed}

\subsubsection{Buprenorphine (INN)}

\section{Substance identification}

Buprenorphine (INN) is chemically 21-cyclopropyl-7-alpha-[(S)-1-hydroxy1,2,2-trimethylpropyl]-6,14-endo-ethano-6,7,8,14-tetrahydrooripavine (CAS 53152-21-9 for the hydrochloride; 52485-79-7 for the free base).

\section{Previous review}

In 1989, a decision of the United Nations Commission on Narcotic Drugs placed buprenorphine (INN) in Schedule III of the Convention on Psychotropic Substances (1971 Convention). The decision followed the recommendation of the Expert Committee on Drug Dependence at its twenty-fifth meeting (9). During its thirty-second meeting in 2000 (7), the Committee considered the question of the scheduling of buprenorphine and recommended critical review of the substance, taking into account a request by the INCB, as well as questions concerning the rationale for the control of this substance under the 1971 Convention rather than the 1961 Single Convention.

At its thirty-third meeting, the Committee commenced the critical review of the scheduling of buprenorphine on the basis of a review document produced by the Secretariat (3). The Committee considered that buprenorphine met the requirements both for scheduling in the 1961 Convention and for its present scheduling in the 1971 Convention. However, taking any decision was hindered by a lack of authoritative guidance on the choice between the two possibilities. Therefore, the Expert Committee had to seek guidance for 
its decision from the Conventions, from the existing guidelines and from an appreciation of the impact of changes in the scheduling on public health.

\section{New information since 2002}

A document provided by the Secretariat for the thirty-fourth meeting of the Committee indicated an expansion in the therapeutic role of buprenorphine. Buprenorphine (and other medicines used in agonist pharmacotherapy of opioid dependence, such as methadone) is recognized as an efficacious and cost-effective treatment for opioid dependence. Buprenorphine maintenance treatment programmes provide opportunities for human immunodeficiency virus (HIV)/AIDS prevention among opioid-dependent injecting drug users and also support the implementation of directly observed antiretroviral therapy (ART) for people with opioid dependence who also have HIV/ AIDS. Buprenorphine maintenance treatment programmes can also act as a platform for promoting adherence to medical treatment of opportunistic infections. Buprenorphine maintenance treatment was stated to be available in about 30 countries. In March 2005, WHO included buprenorphine in the 14th WHO Model List of Essential Medicines for use in opioid agonist therapy of opioid dependence (10).

Data were presented to the Committee demonstrating unique pharmacological actions of buprenorphine, which distinguish it from other opioids controlled under the Single Convention. Specifically, buprenorphine is also an agonist at the ORL-1 receptor in the brain, which affects its $\mu$-opioid actions. These new findings suggest that buprenorphine has a unique spectrum of pharmacological actions.

There have been reports of diversion, seizures and abuse of buprenorphine in various countries. It was reported that in many instances buprenorphine was being illegally used for alleviating symptoms of opioid withdrawal.

\section{Additional considerations}

Additional documents presented to the Committee at its thirty-fourth meeting dealt primarily with the possible effects of rescheduling buprenorphine from the 1971 Convention to the 1961 Convention.

The Committee was informed that this question had been discussed during the 115th meeting of the WHO Executive Board. It was indicated during the discussion that the transfer of substances from one convention to the other would result in problems with implementation of the conventions in national laws. A concern was expressed that transfer could consequently give rise to 
rescheduling at the national level, which would have the unintended effect of restricting access to buprenorphine for use in opioid agonist therapy. Of the 56 countries that responded to the WHO questionnaire, 14 stated that such a rescheduling would result in impeded access to treatment.

The documents presented to the meeting also discussed the legal considerations relating to the transfer of substances between conventions. Taking into account the text of the Single Convention on narcotic drugs and the United Nations Convention on psychotropic substances as well as official commentaries to both Conventions and information included in WHO guidelines for the review of dependence-producing psychoactive substances for international control, it is advisable that a substance should not be under more then one Convention. The WHO guidelines give guidance for the scheduling of new drugs, not yet scheduled, and on the choice between the Conventions for those drugs. They also give guidance for the scheduling of drugs already in the 1988 Convention. However, the guidelines do not give guidance on the transfer of a substance from the 1961 to the 1971 Convention or vice versa. A transfer of a substance from one Convention to the other would demand that the United Nations Commission on Narcotic Drugs take a simultaneous decision on deletion of a substance from one Convention and adding it to the appropriate schedule of another Convention. A procedure for making a deletion from the schedules of the 1971 Convention is included in article 2 para. 6 of the Convention and requires a new assessment by WHO. A similar provision is included in the 1961 Convention article 3 para. 6(b). No provision is included, however, to indicate that these decisions are to be taken simultaneously.

\section{Discussion}

In the course of the meeting, members of the Committee expressed their views concerning various aspects of the current scheduling status of buprenorphine and the possible consequences, including legal aspects, of its rescheduling. It became evident that there were divergent views on the legal situation related to the transfer of substances between Conventions. The majority of the members considered however that the Expert Committee on Drug Dependence is not properly constituted to discuss legal issues related to international treaties.

\section{Recommendation}

Following review of the documents presented at the present meeting, which expanded the information made available at its thirty-third meeting, the 
Committee considered the unique pharmacological actions of buprenorphine, and its expanded role in the treatment of opioid dependence. This pharmacological treatment of opioid dependence also contributes to the efficient prevention and treatment of HIV/AIDS among opioid-dependent injecting drug users. Hence, the Committee did not recommend any change in the present scheduling of the substance in Schedule III of the 1971 Convention.

\subsubsection{Butorphanol (INN)}

\section{Substance identification}

Butorphanol (INN) is chemically (-)-17-(cyclobutylmethyl)morphinan3,14-diol.

\section{Previous review}

Butorphanol was pre-reviewed by the Committee at its thirty-third meeting in September 2002 (3). The Committee recommended a critical review based on reports of abuse in some countries.

\section{Similarity to known substances and effects on the central nervous system}

Butorphanol is a synthetic opioid partial agonist analgesic with properties similar to other $\mu$-opioid agonists such as scheduled substances buprenorphine and pentazocine. Although in radioligand-binding studies, butorphanol binds to both $\mu$ - and $\kappa$-opioid receptors, most of the observed behavioural, pharmacological and therapeutic effects appear to be due to its $\mu$-opioid receptor agonist activity. Early studies suggested that butorphanol did not produce complete respiratory depressant effects and a "plateau" or "ceiling effect" was observed although more recent studies have challenged this notion. Moderate adverse effects on the central nervous system such as nausea/vomiting, headache, clamminess, sweatiness, asthenia, paraesthesia, sedation, lethargy, anxiety, nervousness, euphoria, vertigo, dizziness, floating feeling, confusion and light-headedness are often reported following both parenteral and intranasal administration.

\section{Dependence potential}

Early preclinical studies in laboratory animals suggested that butorphanol has lower abuse potential than full $\mu$-agonists such as morphine. Human studies have indicated that although the incidence of butorphanol dependence is infrequent, the withdrawal symptoms are very similar to those observed for morphine and buprenorphine. Information on the abuse potential 
of the different formulations of butorphanol shows that, from a pharmacological viewpoint, the trans-nasal preparation does not appear to differ in its abuse liability from the parenteral preparations. However, other nonpharmacological factors such as availability and pattern of use can play critical roles in the likelihood of its abuse.

\section{Actual abuse and/or evidence of likelihood of abuse}

Abuse and diversion have been reported by very few countries - only two countries of the 74 that responded to the WHO questionnaire mentioned abuse of butorphanol.

\section{Therapeutic usefulness}

Butorphanol is used medically in humans as an analgesic for the relief of moderate-to-severe acute pain in certain specific conditions such as postsurgical pain or migraine. Butorphanol was stated as being available for medical use in 21 of the 74 countries that responded to the WHO questionnaire. It is also used in veterinary medicine as an analgesic and antitussive agent.

\section{Recommendation}

After reviewing the information available, the Committee considered that the level of abuse of butorphanol is low, limited to a few countries and does not pose a risk to public health. Therefore, the Committee did not recommend scheduling of butorphanol.

\subsubsection{Ketamine (INN)}

\section{Substance identification}

Ketamine (INN) is ( \pm )-2-(o-chlorophenyl)-2-(methylamino)cyclohexanone. It contains a chiral centre, resulting in two enantiomers: $S-(+)$-ketamine and $R$-(-)-ketamine. Usually, the racemate is marketed but the more active $S-(+)-$ enantiomer is increasingly present in commercially available preparations.

\section{Previous review}

Ketamine was pre-reviewed by the Committee at its thirty-third meeting and critical review was recommended on the basis of reports of abuse in various countries (3).

\section{Similarity to known substances and effects on the central nervous system}

Ketamine is an arylcycloalkylamine structurally related to cyclidines such as phencyclidine. It is a non-competitive NMDA-receptor antagonist that 
affects the central nervous system, resulting in hallucinations, disturbances in thinking, perception and motor function and may also produce mild respiratory depression. It is used as an anaesthetic in both human and veterinary medicine.

\section{Dependence potential}

Various animal models have shown that ketamine can produce a state of dependence, but reports of such dependence in humans are very limited. Tolerance may occur, but there is no evidence of a withdrawal syndrome.

\section{Actual abuse and/or evidence of likelihood of abuse}

Abuse has been reported in a number of countries in the Americas, Asia and Europe, sometimes in a mixture with other substances.

\section{Therapeutic usefulness}

Ketamine is widely used as an anaesthetic and analgesic in human and veterinary medicine. Ketamine was stated as being available for medical use in 70 out of the 74 countries that answered the WHO questionnaire. It is included as a general anaesthetic in the 14th WHO Model List of Essential Medicines (10).

\section{Recommendation}

The Committee reviewed the information contained in the critical review document and concluded that this information was not sufficient to warrant scheduling. However, in the course of the meeting, the Committee was informed that the United Nations Commission for Narcotic Drugs at its 49th session, held in March 2006, had adopted a draft resolution for transmission to ECOSOC, on the listing of ketamine as a controlled substance (11). The Committee requested the Secretariat to produce an updated version of the critical review and present it to the next meeting of the Expert Committee on Drug Dependence.

\subsubsection{Khat (Catha edulis Forsk.)}

\section{Substance identification}

Khat refers to the leaves and the young shoots of the plant Catha edulis Forsk., a species belonging to the plant family Celastraceae. It is also written and/or known as qat, q'at, kat, kath, gat, chat, tschat (Ethiopia), miraa (Kenya) and murungu. The dried leaves of khat are known as Abyssinian tea or Arabian tea. 


\section{Previous review}

Khat had been considered and reviewed by the Expert Committee many years previously, and at its thirty-third meeting the Committee pre-reviewed khat and concluded that there was sufficient information on this substance to justify a critical review (3).

\section{Similarity to known substances and effects on the central nervous system}

The major psychoactive compounds found in khat are cathinone and cathine (norpseudoephedrine), which are scheduled under the 1971 Convention, and norephedrine, which is controlled under the 1988 Convention. The plant contains only the (-)-enantiomer of cathinone, which has the same absolute configuration as $S$-(+)-amphetamine. Use of khat produces a state of euphoria and increased alertness. It can also produce insomnia and an increase in blood pressure, heart rate and body temperature. Psychotic reactions induced by khat use have also been reported.

\section{Dependence potential}

There is inconsistent data regarding the dependence potential of khat. Withdrawal symptoms after prolonged use may include loss of energy, lethargy, depressive feelings and slight trembling, but these symptoms are mild and resolve rapidly. Some tolerance may also develop.

\section{Actual abuse and/or evidence of likelihood of abuse}

Khat leaves are chewed habitually in the south-western part of the Arabian Peninsula and in East Africa. However, khat chewing has spread to other African countries and to Australia, Europe and the USA. Daily consumption of khat may have negative effects on the social and economic life of the user. Khat is used in social gatherings.

\section{Therapeutic usefulness}

No confirmed therapeutic usefulness has been identified for khat.

\section{Recommendation}

The Committee reviewed the data on khat and determined that the potential for abuse and dependence is low. The level of abuse and threat to public health is not significant enough to warrant international control. Therefore, the Committee did not recommend the scheduling of khat.

The Committee recognized that social and some health problems result from the excessive use of khat and suggested that national educational 
campaigns should be adopted to discourage use that may lead to these adverse consequences.

\subsubsection{Zopiclone (INN)}

\section{Substance identification}

Zopiclone (INN) is chemically 4-methyl-1-piperazinecarboxylic acid ester with 6-(5-chloro-2-pyridyl)-6,7-dihydro-7-hydroxy-5 $\mathrm{H}$-pyrrolo[3,4-b]pyrazin-5-one. Zopiclone has one chiral centre and therefore exists in two enantiomeric forms and a racemate. It is marketed under many trade names. Eszopiclone is the $S$-(+)-enantiomer and has also been marketed recently.

\section{Previous review}

Zopiclone was pre-reviewed by the Committee at its twenty-ninth meeting, at which it recommended continued surveillance but not a critical review (12). Zopiclone underwent pre-review at its thirty-third meeting and the Committee recommended critical review based on its abuse liability and the significant number of adverse drug reaction reports related to abuse, received by the international drug monitoring programme (3).

\section{Similarity to known substances and effects on the central nervous system}

The pharmacological properties of zopiclone are very similar to those of benzodiazepines and are believed to be related to the binding to the $\gamma$-aminobutyric acid (GABA)/benzodiazepine receptor complex. Zopiclone has a sedative action on the central nervous system producing sedation, somnolence, fatigue and impairment of concentration. Other side-effects include nausea, dizziness, headache, sweating, hallucinations and agitation.

\section{Dependence potential}

Zopiclone use can lead in some instances to dependence with associated tolerance and withdrawal syndrome.

\section{Actual abuse and/or evidence of likelihood of abuse}

Some abuse of zopiclone has been reported by six of the countries that responded to the WHO questionnaire. In addition, abuse has been reported

This is synonymous with (5RS)-6-(5-chloro-2-pyridyl)-6,7-dihydro-7-oxo-5H-pyrrolo[3,4-b]pyrazin5-yl 4-methylpiperazine-1-carboxylate. 
as an adverse drug reaction to the WHO Programme for International Drug Monitoring. Zopiclone has also been implicated in some cases of sexual assault and robbery.

\section{Therapeutic usefulness}

Zopiclone is a widely prescribed hypnotic primarily used in the treatment of insomnia. Zopiclone was stated as being available for medical use in 34 of the 59 countries that responded to the questions on this substance in the WHO questionnaire.

\section{Recommendation}

On the basis of available data concerning the pharmacological profile and dependence potential of zopiclone, the Committee rated the abuse liability to be low, whereas the therapeutic usefulness is considerable. The Committee therefore came to the conclusion that zopiclone does not warrant international control and therefore did not recommend its scheduling.

\section{Pre-review of psychoactive substances}

The review of psychoactive substances by WHO is carried out in two steps. The first step is referred to as pre-review; this is a preliminary review carried out by the Committee to determine whether or not a fully documented review (critical review) of the substance is required. The criterion for judgement as to whether critical review is necessary is whether or not WHO has information that might justify the scheduling of the substance. In the case of psychotropic substances, this requires information on actual abuse of the drug that causes significant public health and social problems in more than one country.

In addition to the Secretariat, any member of the Expert Committee, or any representative of the other organizations invited to participate in the Expert Committee meeting, can submit a proposal to pre-review a substance together with supporting information. At the present meeting, tramadol and gamma-hydroxybutyric acid were proposed by the Secretariat.

\subsection{Gamma-hydroxybutyric acid}

Gamma-hydroxybutyric acid (GHB) was pre-reviewed by the Committee at its thirty-first meeting (13) and critically reviewed at its thirty- 
second meeting (7). It was recommended for inclusion in Schedule IV of the 1971 Convention and since 2001 has been placed in this Schedule by a decision of the United Nations Commission on Narcotic Drugs.

GHB is a naturally occurring compound found in very low concentrations in mammalian tissues. It is considered to act by binding to GHB-specific receptors and $\mathrm{GABA}_{\mathrm{B}}$ receptors. At pharmacological doses it acts as a central nervous system depressant. In some countries, GHB is used clinically as an anaesthetic agent and in the treatment of narcolepsy, narcolepsy with cataplexy, alcohol withdrawal and myoclonus-dystonia. GHB can produce physical dependence together with a withdrawal syndrome when the drug is abruptly discontinued following regular, chronic use. The withdrawal syndrome appears to be similar to that of other central nervous system depressants. GHB and related products (gamma-butyrolactone and 1,4-butanediol) have been abused for their purported sexual performance-enhancing and growth-promoting effects as well as their euphoric effects. There have been reports of GHB being used to facilitate sexual assault. The toxicity of GHB is dose-dependent and there have been numerous instances of fatal and non-fatal GHB intoxication in many countries. The mode of abuse frequently involves other substances such as methylenedioxy-N-methylamphetamine (MDMA) and alcohol. Use and abuse of GHB appears to occur mainly in Australia, Europe and the USA.

\section{Recommendation}

The Committee considered additional data regarding its abuse liability and toxicity and recommended that a new critical review of GHB would be appropriate to consider its possible rescheduling.

\subsection{Tramadol (INN)}

Tramadol (INN) is ( \pm )-trans-2-[(dimethylamino)methyl]-1-(3-methoxyphenyl)cyclohexanol. It was critically reviewed at the thirty-third meeting of the Committee in 2002, but the Committee decided that the information available at that time was not sufficient to recommend international control of tramadol, although it was adequate to recommend that WHO keep the drug under surveillance (3). Subsequently, the substance was presented by the WHO Secretariat for pre-review at the present meeting.

Tramadol is a centrally acting synthetic opioid analogue of codeine with a weak affinity for the opioid receptors. It has additional monoaminergic activity (serotonin and noradrenaline re-uptake inhibition and $\alpha_{2}$-adrener- 
gic stimulation) producing a combined analgesic effect. The $O$-desmethyl metabolite is also pharmacologically active owing to significant $\mu$-opioid receptor affinity. Tramadol induces analgesia, but is associated with less respiratory depression than other opioids and has no significant cardiac effects. It has been found to reduce the seizure and sweating thresholds, and to reduce postoperative shivering. Subjective effects include euphoria. Reported adverse effects have included: dizziness, headache, agitation, nausea, vomiting and seizures. Overdose has been reported to result in tachycardia, convulsions, respiratory depression and coma. Other centralnervous-system depressant or monoamine antidepressant compounds may exacerbate any toxic effects. There have been some reported instances of non-fatal and fatal tramadol intoxication worldwide, but these are few in comparison to total patient exposure.

Preclinical studies in animals indicated that tramadol may have a low abuse potential. Clinical studies and postmarketing surveillance programmes have found a possibility of dependence and abuse, particularly in patients with a previous history of opioid dependence or abuse. Postmarketing surveillance programmes have shown a rate of abuse of 0.5-1 per 100000 patients (1997-2003). This figure included generic products since 2002 and tramadol with paracetamol combinations during 1997-2003.

Data from various monitoring organizations reported some instances of smuggling and diversion but did not show any increasing trend in tramadol abuse and there was no evidence of illicit manufacture.

\section{Recommendation}

Following review of the documents presented at the present meeting, which expanded the information made available at the thirty-third meeting, the Committee considered that, even after a recent major increase in the extent of its use because of its therapeutic usefulness, tramadol continues to show a low level of abuse. Hence, the Committee concluded that there was not sufficient evidence to justify a critical review.

\section{Substances identified for future pre-review}

\subsection{Gamma-butyrolactone (GBL)}

During the pre-review of GHB, the Committee noted information relating to the abuse of GBL itself (convertible to GHB in the body) and suggested this substance for pre-review. 


\subsection{1,4-Butanediol}

During the pre-review of GHB, the Committee noted information relating to the abuse of 1,4-butanediol itself (convertible to GHB in the body) and suggested this substance for pre-review.

\section{Guidelines for the WHO review of dependence- producing psychoactive substances for international control}

\subsection{Amending the current version of the guidelines}

International control of narcotic drugs and psychotropic substances is based on two treaties: the 1961 United Nations Single Convention on Narcotic Drugs and the 1971 United Nations Convention on Psychotropic Substances. Both Conventions include schedules listing substances that are subject to appropriate control measures. The Conventions also established mechanisms for expanding and modifying the schedules and designated the United Nations Commission on Narcotic Drugs as the body authorized to adopt pertinent decisions concerning the scheduling of substances.

The Conventions specify the role of WHO as the institution designated to provide the United Nations Commission for Narcotic Drugs with appropriate information and evaluations related to medical, scientific and public health aspects of scheduling individual substances. Such assessment may pertain to substances that are not yet under international control, but also, to amendment of existing schedules or to deletion of substances from a schedule.

The responsibility for the assessment of substances for international control has been entrusted within WHO to the Expert Committee on Drug Dependence, which reviews relevant information and gives its advice to the Director-General of WHO. The review is carried out with the considerable assistance of the WHO Secretariat according to a procedure approved by the WHO Executive Board. The current version of the procedure is included in the WHO document WHO/EDM/QSM/2000.5 entitled Guidelines for the WHO review of dependence-producing psychoactive substances for international control which was approved by the WHO Executive Board in decision EB105 in 2000 (14).

During its thirty-third meeting, the Expert Committee noted certain issues related to the scheduling of some substances for which no specific advice 
exists in the current guidelines. The Committee therefore requested that the WHO Secretariat develop additional guidelines that would be suitable for amending their present text. A draft of such supplementary guidelines was produced in 2003 and presented to the WHO Executive Board for review and possible approval. The Executive Board discussed this proposal during its 114th and 115th meetings and, at the 115th meeting, the Executive Board confirmed the applicability of the current version of the guidelines and asked the Secretariat and the Expert Committee to continue their work on the issue $(15,16)$.

During its thirty-fourth meeting, the Committee took note of the decision of the Executive Board. The Committee asked the Secretariat to continue to provide proposals for the necessary amendments to the guidelines, taking into account new developments that relate to the needs of international control of dependence-producing psychoactive substances. The Committee also decided that to facilitate future opinions related to the scheduling of psychoactive substances in situations that are not fully covered by the current version of the guidelines, it will proceed according to an interpretation of specific situations as described below in item 5.2.

The Committee also considered that the impact of scheduling on the balance between medical availability and prevention of abuse of controlled substances should become a part of the critical review.

\subsection{Interpretation of specific aspects of the guidelines}

The Committee decided that the stage of "pre-review" described in the guidelines should pertain not only to the review of psychoactive substances that were not previously scheduled in international Conventions, but also to the initial step of the review of substances that have already been scheduled in either of the Conventions. If the situation arises in which such a substance has to be considered for rescheduling or for deletion from a schedule, as indicated in para. 13 of the Guidelines, such pre-review can be initiated by the WHO Secretariat, individual members of the Expert Committee, or by representatives of organizations invited to participate in the meetings of the Committee. A pre-review procedure can also be initiated in cases when the Committee has recommended to the WHO Secretariat that a given substance should be subject to surveillance and its results indicate a need for such a review.

With respect to the "critical review" stage of the procedure described in para. 15 of the guidelines, the Committee decided that this should 
preferably be concluded during a single meeting. However, in cases where additional information concerning the substance under review is required, the Committee may decide that it will reach a final opinion at a subsequent meeting.

\subsection{Access to information necessary for the evaluation of substances}

The Expert Committee decided to advise the Secretariat to draw the attention of countries to the fact that both the Conventions include procedures for informing the United Nations: where a party has information, which, in its opinion, might require an amendment to any of the Schedules, it should notify the Secretary-General and furnish him or her with the information in support of the notification, after which the Secretary-General will transmit such notification to WHO and others.

The countries committed themselves to follow these procedures when becoming party to the Conventions, but the Expert Committee found that this procedure had not been followed by any country in recent years, although the Committee knows of cases in which this would have been appropriate.

The Committee also advises the Secretariat to urge countries once more to respond to questionnaires sent out by WHO in the preparation process for the evaluation of substances.

\section{Other matters}

\subsection{Activities of the European Monitoring Centre for Drugs and Drug Addiction (EMCDDA)}

Dr Roumen Sedefov, Project Manager for New Drugs and the Scientific Committee at the European Monitoring Centre for Drugs and Drug Addiction (EMCDDA) based in Lisbon, Portugal, described the role of the European Union (EU) drugs agency. He also outlined the implementation process of the Council Decision 2005/387/JHA of 10 May 2005 on the information exchange, risk assessment and control of new psychoactive substances. The Decision establishes a mechanism for the rapid exchange of information at EU level on new psychoactive substances that may pose a public health threat similar to that posed by those listed in the 1961 United Nations Single Convention on Narcotic Drugs and the 1971 United Nations Convention on Psychotropic Substances. 


\subsection{Use of pharmacovigilance data for the assessment of dependence and abuse potential (procedures and methodology)}

The Committee was informed by the Secretariat on the WHO Programme for International Drug Monitoring. The Programme dates back to 1968 and is run by the Secretariat, WHO Collaborating Centre (Uppsala Monitoring Centre) and its National Centres (79 to date) and Associate Members (18 to date). The number of case-reports of adverse drug reactions in the WHO database exceeds 3.5 million - an annual increase of 160000 .

For the pre-reviews and critical reviews, data obtained from the WHO Collaborating Centre were incorporated into the review reports. However, the Committee made several suggestions that could improve the usefulness of the data. These included the use of comparison substances, selection of adverse reactions which are indicators of drug abuse, better specification of the terms used and the use of denominator data, all of which could improve interpretation of the information.

It was agreed that the Secretariat would organize a discussion on how to make the best use of these data for the evaluation of dependence and abuse potential. Experts and others involved will be invited to participate. It was also agreed that the collaboration between the Expert Committee and the Programme would be intensified.

\subsection{Promotion of education and information on the appropriate use of psychoactive drugs}

At its thirty-third meeting, the Expert Committee discussed the possible adverse consequences of the medical use of selective serotonin reuptake inhibitors (SSRIs) (3). The Committee recommended that SSRIs be placed on the agenda for consideration at the next meeting of the Committee, not in the context of control, but to promote education and information on the appropriate use of psychoactive drugs. For this reason the issue was on the agenda of the thirty-fourth meeting of the Committee, but was expanded to medicines that are currently under international control (controlled medicines).

In 2005, the World Health Assembly and ECOSOC requested the INCB and WHO to examine the feasibility of a possible assistance mechanism that would facilitate the adequate treatment of pain using opioid analgesics (resolutions ECOSOC 2005/25 and WHA58.22). During its thirtyfourth meeting, the Committee noted — as it had already concluded on 
other occasions - that access to controlled medicines is insufficient in many cases, and it was therefore regarded as appropriate to establish an assistance mechanism that addresses the access to and the rational use of such medicines. Therefore, the Committee agreed that it could play a role in the promotion of education and information on the appropriate use of controlled medicines.

The Secretariat is working on a plan to improve access to and rational use of controlled medicines. The Committee recommended that a formal and regularly accessible forum would enhance the consultation of experts in this field and the Expert Committee is willing to act as such.

\subsection{Impact of international control on medical availability of substances}

During the discussions, factors limiting the availability of drugs for medical use were identified, including barriers inadvertently created by the application of laws and regulations. There are countries where stricter measures are applied than are required by the Conventions. This is permissible, as the requirements of the Conventions are minimum requirements. However, the aims of the Conventions are to ensure availability for medical use as well as the prevention of abuse. It should be noted therefore that the Conventions do not require the parties to implement specific licensing for prescribing and dispensing controlled substances for medical use, nor require permits for receiving these substances therapeutically. Applying stricter measures than those required by the Conventions may hamper rational use of medicines. The appropriate national authorities should carefully consider whether any such measure currently in force could be modified to permit access for patients in need.

The scheduling of a substance may lead to significant barriers to its availability as a medicine. In addition to measures of control stricter than those contemplated by the Conventions, as mentioned above, other reasons may include inadequate implementation of accompanying measures, such as failure to develop and submit accurate estimates and statistics to the INCB, inappropriate medical practices and insufficient recognition of the therapeutic usefulness of controlled medicines by medical professionals, legislators and law enforcement officers.

It was noted by the Committee that over $80 \%$ of the world's population has no proper access to narcotic analgesics, if required. The Committee stressed 
that the appropriate national authorities should be encouraged to cooperate with WHO in consultation with the INCB to assist in improving access to these medications.

The Committee requested the WHO Secretariat to suggest including on the proposed agenda of the next Committee meeting, a discussion of the impact of scheduling on the balance between medical availability of controlled substances and the prevention of their abuse. 



\section{Acknowledgements}

The Committee wishes to acknowledge the contribution made to its discussions by Dr A. Ball, Department of HIV/AIDS, and Dr S.N. Pal and Ms C. Scudamore, Department of Medicines Policy and Standards, WHO, Geneva, Switzerland.

It also wishes to acknowledge the Fundacion De Lima Bohmer, Colombia, for financial support enabling WHO to publish this report in Spanish.

\section{References}

1. Single Convention on Narcotic Drugs, 1961, as amended by the 1972 Protocol amending the Single Convention on Narcotic Drugs, 1961. New York, United Nations, 1972.

2. Convention on Psychotropic Substances, 1971. New York, United Nations, 1977.

3. WHO Expert Committee on Drug Dependence. Thirty-third report. Geneva, World Health Organization, 2003 (WHO Technical Report Series, No. 915).

4. WHO Expert Committee on Drug Dependence. Twenty-sixth report. Geneva, World Health Organization, 1989 (WHO Technical Report Series, No. 787).

5. WHO Expert Committee on Drug Dependence. Twenty-seventh report. Geneva, World Health Organization, 1991 (WHO Technical Report Series, No. 808).

6. Report of the thirty-fourth session (29 April-9 May 1991). Economic and Social Council, Commission on Narcotic Drugs, Official Records, 1991, Supplement No. 4. New York, United Nations, 1991 (E/1991/24, E/Cn.7/1991/26).

7. WHO Expert Committee on Drug Dependence. Thirty-second report. Geneva, World Health Organization, 2001 (WHO Technical Report Series, No. 903).

8. United Nations Convention against Illicit Traffic in Narcotic Drugs and Psychotropic Substances, 1988. New York, United Nations, 1991.

9. WHO Expert Committee on Drug Dependence. Twenty-fifth report. Geneva, World Health Organization, 1989 (WHO Technical Report Series, No. 775).

10. WHO Model List of Essential Medicines, 14th edition, Geneva, World Health Organization, 2005.

11. Listing of ketamine under the Convention on Psychotropic Substances of 1971, draft resolution. Vienna, Economic and Social Council, Commission on Narcotic Drugs, 49th session, 2006 (E/CN.7/2006/L.11).

12. WHO Expert Committee on Drug Dependence. Twenty-ninth report. Geneva, World Health Organization, 1995 (WHO Technical Report Series, No. 856).

13. WHO Expert Committee on Drug Dependence. Thirty-first report. Geneva, World Health Organization, 1999 (WHO Technical Report Series, No. 887). 
14. Guidelines for the WHO review of dependence-producing psychoactive substances for international control. Geneva, World Health Organization, 2000 (reprinted from document EB 105/2000/REC/1, Annex 9).

15. Summary Records: Executive Board, 114th Session. Geneva, World Health Organization, 2004.

16. Summary Records: Sixth meeting, Executive Board, 115th Session. Geneva, World Health Organization, 2005. 




\section{WHO Expert Committee on Drug Dependence}

Thirty-third report.

WHO Technical Report Series, No. 915, 2003 (25 pages)

\section{WHO Expert Committee on Drug Dependence}

Thirty-second report.

WHO Technical Report Series, No. 903, 2001 (26 pages)

\section{WHO Expert Committee on Drug Dependence}

Thirty-first report.

WHO Technical Report Series, No. 887, 1999 (28 pages)

\section{The Selection and use of Essential Medicines}

Report of the WHO Expert Committee, 2005 (including the 14th Model List of Essential Medicines)

WHO Technical Report Series, No. 933, 2006 (119 pages)

\section{WHO/UNODC/UNAIDS position paper}

Substitution maintenance therapy in the management of opioid dependence and HIV/AIDS prevention

World Health Organization, United Nations Office on Drugs and Crime, Joint United Nations Programme on HIV/AIDS, 2004

Cancer pain relief, with a guide to opioid availability, 2 nd ed. 1996 (69 pages)

\section{Cancer pain relief and palliative care in children}

1998 (85 pages)

Achieving Balance in National Opioids Control Policy, guidelines for assessment, WHO/EDM/QSM/2004.4, WHO, Geneva, 2000

(also available in 22 languages on http://www.medsch.wisc.edu/painpolicy/publicat/00whoabi/00whoabi.htm) 
This report presents the recommendations of a WHO Expert Committee responsible for reviewing information on dependence-producing drugs to assess the need for their international control. The first part of the report contains a summary of the Committee's evaluations of seven substances (dronabinol, oripavine, buprenorphine, butorphanol, ketamine, khat and zopiclone). The report also discusses the substances that were pre-reviewed (gamma-hydroxybutyric acid and tramadol) and recommended gamma-hydroxybutyric acid for critical review at a future meeting. Two substances (gamma-butyrolactone and 1,4-butanediol) were identified for future pre-review). The second part of the report discusses the guidelines for the WHO review of dependence-producing psychoactive substances for international control. It includes sections on amending the current guidelines, interpretation of specific aspects of the guidelines and access to information necessary for the evaluation of substances. The final section considers other matters including activities of the EMCCDA, the use of pharmacovigilance data, promotion of education and information on the appropriate use of psychoactive drugs and the impact of international control on medical availability of substances. 